\title{
Child maltreatment syndrome: demographics and developmental issues of inpatient cases
}

\author{
Xin Ying Ngiam $^{1,2}$, MMed, fams, Ying Qi Kang ${ }^{1,2}$, MMed, FAMs, Ramkumar Aishworiya ${ }^{1,2}$, MRCPCH, MMed, \\ Jennifer Kiing ${ }^{1,2}$, FRACP, FAMS, Evelyn Chung Ning Law ${ }^{1,2}$, MD
}

INTRODUCTION This study aimed to describe the demographic, social, developmental and behavioural profile of children hospitalised for alleged child maltreatment syndrome (CMS).

METHODS This study was a retrospective review of the consecutive inpatient records of children (0-16 years) admitted to the National University Hospital, Singapore, for alleged CMS over a three-year period. Descriptive data on the demographic characteristics, alleged maltreatment, medical and developmental histories, and family background of these children were collected and analysed. Chi-square statistics were used to test whether family factors were associated with the type of maltreatment and the presence of developmental disorders.

RESULTS A total of 89 children, who accounted for 90 admission cases, were studied. Physical abuse (70.0\%) was the most common, followed by neglect (11.1\%) and sexual abuse (7.8\%). Child protection services had already been involved in $29.2 \%$ of the cases prior to the child's admission. Children who were victims of abuse were more likely to come from homes with a prior history of domestic violence $(p=0.028)$. Financial difficulty was found to be a risk factor for neglect $(p=0.005)$. Among the 89 children, $15.7 \%$ were found to have developmental disorders and $10.1 \%$ had mental health diagnoses. Children who had developmental disorders were more likely to have a parent with a mental health disorder $(p=0.002)$.

CONCLUSION A sizeable proportion of the children admitted for alleged CMS had developmental or behavioural disorders. Clinicians have a role in ensuring that these children have appropriate follow-up plans. Children from high-risk families should be screened for maltreatment.

Keywords: abuse, behaviour, child maltreatment, development, nonaccidental injury

\section{INTRODUCTION}

Child maltreatment is defined as all forms of physical and/or emotional ill-treatment, sexual abuse, neglect, negligent treatment, and commercial or other exploitations that result in actual or potential harm to a child's health, development or dignity. ${ }^{(1)}$ Child maltreatment predisposes the child to multiple long-lasting effects, including mental health problems, which in some cases can have lifelong implications and associated costs.

The deleterious consequences of child maltreatment last into adulthood. Studies have shown that adults who were abused as children have significantly higher incidences of mental health problems and ill health. ${ }^{(2,3)}$ In other words, child maltreatment can have long-lasting social and economic repercussions. Research suggests that protective factors such as safe, stable relationships and social support, ${ }^{(4)}$ as well as risk factors such as parental alcohol abuse, ${ }^{(5)}$ can influence the outcomes of children exposed to violence. Thus, knowledge of the profile of children involved in child maltreatment cases can enhance our understanding of the characteristics of such children, which will help us to identify their needs, so as to improve interventions and preventive measures.

Studies from various parts of the world have found associations between child maltreatment and developmental/ behavioural disorders. For example, a population-based retrospective cohort study in the United Kingdom found that children with conduct disorders or moderate-to-severe learning difficulties had the highest odds of being listed on the child protection register for all forms of abuse and neglect. ${ }^{(6)}$ Another example is a descriptive study from Turkey, which found that attention-deficit/hyperactivity disorder (ADHD) was the most common disorder among maltreated children seen in a child psychiatric clinic. ${ }^{(7)}$ In Singapore, the number of reported child abuse cases has been on an upward trend, from 176 cases in 2008 to 247 cases in 2012. ${ }^{(8)}$ In October 2005, a publication by the Ministry of Community, Youth and Sports (MCYS), Singapore, (now known as the Ministry of Social and Family Development [MSF]) highlighted the demographic and social profile of children involved in reported child protection cases from 2000 to 2004. ${ }^{(9)}$ In that publication, it was reported that ill-treatment of abused children was often due to the caregivers' poor understanding of their children's developmental needs, or the lack of ability to cope with their children's challenging behaviours; however, the report did not present the medical conditions and developmental disorders of the children. ${ }^{(9)}$

The present study aimed to describe the profile of children admitted to a tertiary hospital for alleged child maltreatment syndrome (CMS), particularly the proportion of children with medical, developmental or behavioural needs.

${ }^{1}$ Department of Paediatrics, Yong Loo Lin School of Medicine, National University of Singapore, ${ }^{2}$ Khoo Teck Puat-National University Children's Medical Institute, National University Health System, Singapore

Correspondence: Dr Ngiam Xin Ying, Registrar, Khoo Teck Puat-National University Children's Medical Institute, National University Health System, 1 E Kent Ridge Road, NUHS Tower Block Level 12, Singapore 119228. nxy304@hotmail.com 


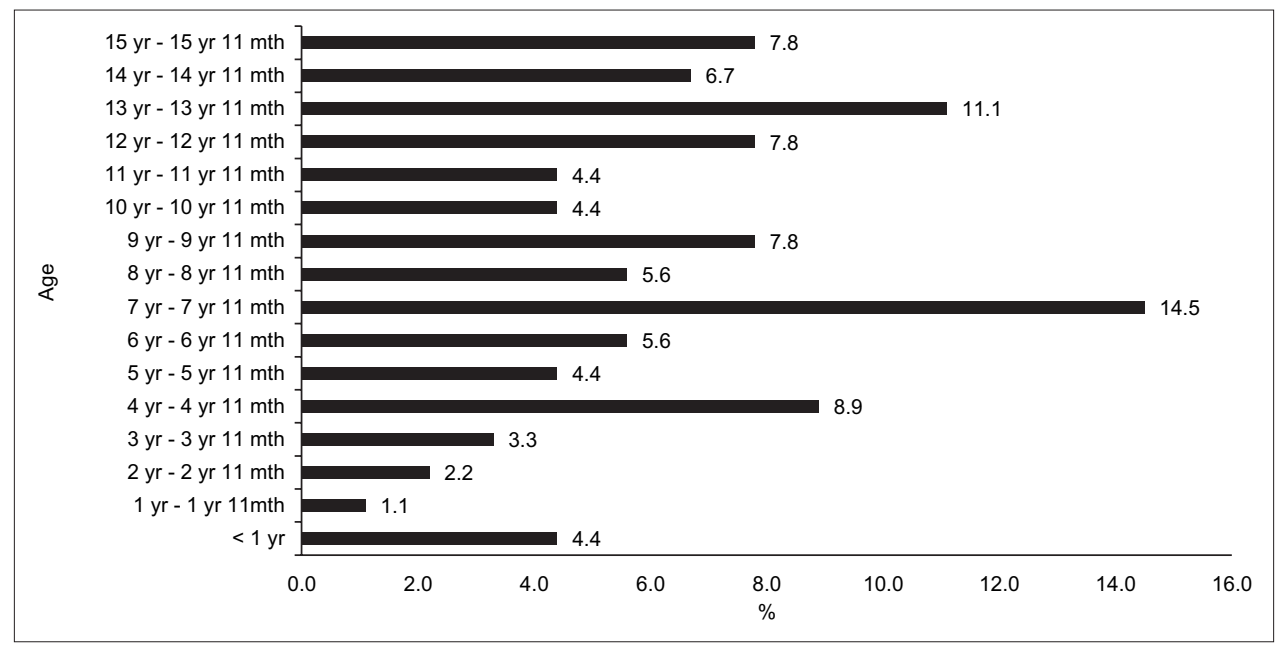

Fig. 1 Bar graph shows the ages of the children at admission $(n=89)$.

\section{METHODS}

This study was a retrospective review of consecutive inpatient records of children aged 0-16 years who were admitted to the National University Hospital, Singapore, (a single tertiary care hospital) between 1 January 2010 and 31 December 2012. We identified all children under the age of 16 years who were admitted to the paediatric unit of the hospital for alleged CMS during the three-year study period and whose medical record showed the International Classification of Diseases (ICD)-9 and ICD-10 codes for CMS (Table I). The study was approved by the Domain Specific Review Board of the National Healthcare Group.

Using a structured data extraction form, the following information was extracted from the case notes: (a) demographic characteristics - age, gender and ethnicity of the child; (b) details of maltreatment - type of abuse, alleged perpetrator and referrer; (c) medical history - chronic medical conditions and history of prematurity; (d) parental concerns of behavioural problems and documented diagnosis of developmental and Axis I mental health problems in the child; (e) socioeconomic background - history of domestic violence, financial difficulty and marital status of parents; (f) history of mental health problems in the main caregiver(s); and (g) placement of child upon discharge with biological parent(s), other family members, foster homes or institutions. Financial difficulty was defined as the need for subsidies, financial assistance or Medifund to pay for medical expenses or provide for the family.

All analyses were conducted using IBM SPSS Statistics version 22.0 (IBM Corp, Armonk, NY, USA). Continuous variables were reported as mean and standard deviation (SD), while categorical variables were reported as percentages. Chi-square statistics were used to find the associations between family factors and the following two categorical variables: type of maltreatment (i.e. abuse or neglect) and presence of a developmental disorder.

\section{RESULTS}

Over the three-year period, there were 90 inpatient admission cases for CMS involving 89 children (one child was admitted
Table I. International Classification of Diseases (ICD) codes used in the identification of child maltreatment syndrome cases in the present study.

\begin{tabular}{|c|c|}
\hline Code & Details \\
\hline ICD-9 & $\begin{array}{l}\text { - 9955: Child maltreatment syndrome } \\
\text { - inclusive of physical, emotional, } \\
\text { nutritional and sexual abuse of child }\end{array}$ \\
\hline ICD-10 & $\begin{array}{l}\text { - T74.0: Neglect or abandonment } \\
\text { - T74.1: Physical abuse } \\
\text { - T74.2: Sexual abuse } \\
\text { - T74.3: Psychological abuse } \\
\text { - T74.8: Other maltreatment syndromes } \\
\text { (mixed forms) } \\
\text { - T74.9: Maltreatment syndrome, } \\
\text { unspecified }\end{array}$ \\
\hline
\end{tabular}

twice within the study period). The mean age of the children was nine years and one month (SD: four years and three months); about $70 \%$ of the children were of school-going age. The peak admission ages for CMS were seven years $(14.5 \%)$ and 13 years (11.1\%). Infants aged less than one year made up a small proportion (4.4\%) of the cohort (Fig. 1). The gender distribution was fairly even, with a slight male preponderance (53.9\%). The children were predominantly of Malay and Chinese ethnicities. The biological father was the alleged perpetrator of the CMS in over half of the cases (Fig. 2). The majority of the children were brought to the hospital by their mother, school staff, MCYS staff or the police (Fig. 3).

At the time of the child's admission to the hospital, child protection services were already involved in 26 of the 89 cases $(29.2 \%)$, as there were prior episodes of alleged maltreatment in the household. Two of these 26 admission cases involved the sibling(s) of the child being investigated for CMS.

Nearly two-thirds $(66.3 \%)$ of the children were from households with a prior history of domestic violence and $46.1 \%$ of the children were from families with reported financial difficulty. In addition, $43.8 \%$ of the children had parents who were divorced or separated, while $4.5 \%$ had experienced the death of a parent (Table II). Among the children who had a parent with a mental health problem $(16.9 \%)$, the most frequently reported parental 


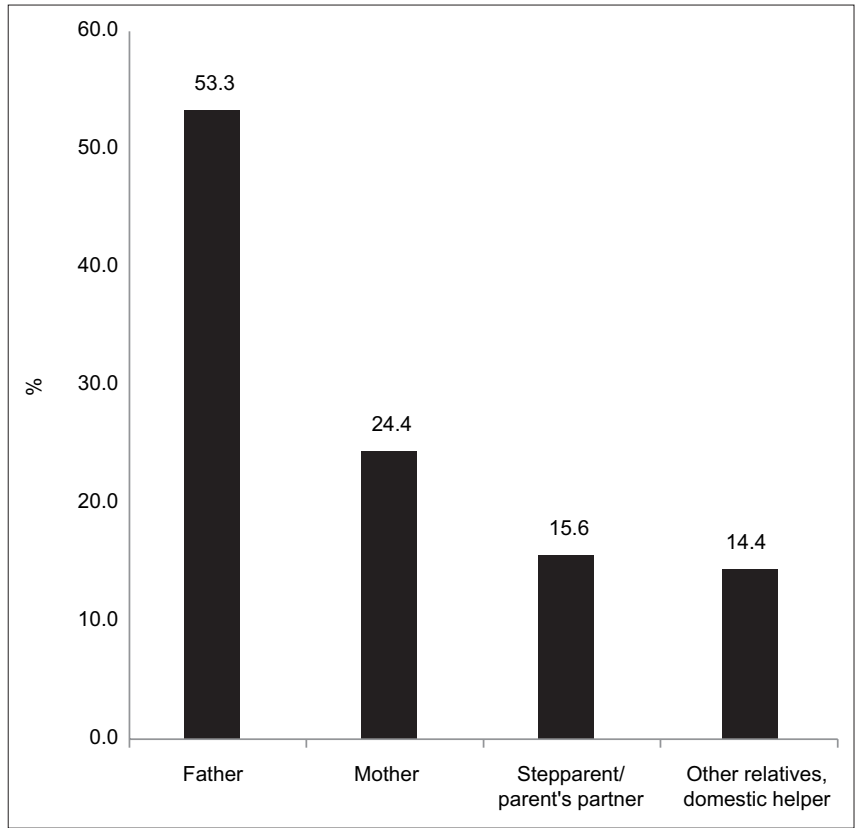

Fig. 2 Bar graph shows the relationship of the alleged perpetrator(s) to the victims of child maltreatment. There was more than one alleged perpetrator in some cases.

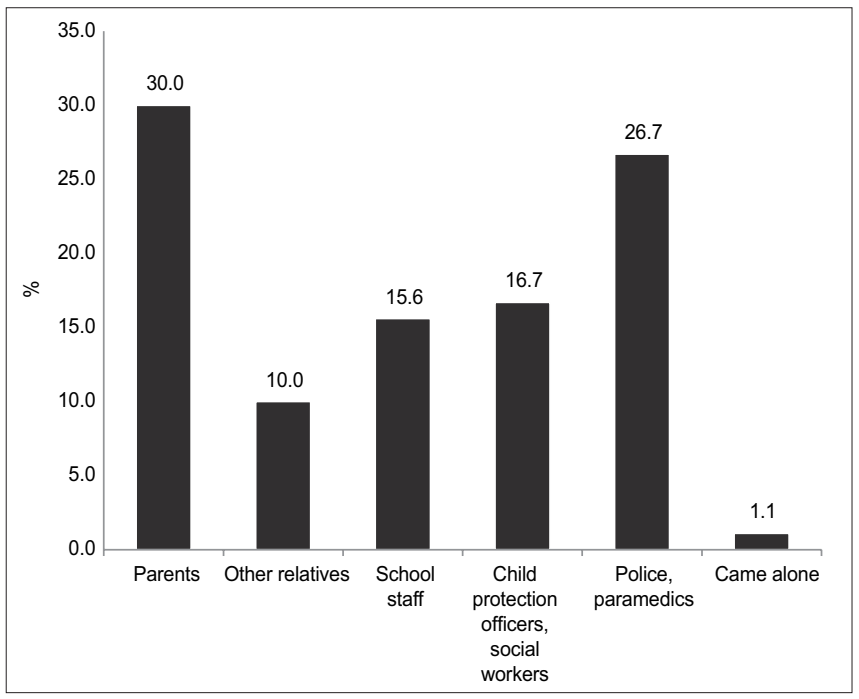

Fig. 3 Bar graph shows the persons who brought the child to medical attention.

condition was alcohol abuse (60.0\%), followed by drug abuse, depression, acute stress reaction and/or intellectual impairment $(40.0 \%)$.

The most frequent form of maltreatment reported was physical abuse (Fig. 4). While the methods of physical abuse varied, the most common ones were hitting or slapping with bare hands, caning, hitting with objects and punching. Neglect was the second most frequent form of maltreatment. Victims of neglect were often admitted as pairs or groups of siblings, and the most common circumstances leading to their admission were abandonment by parents (50.0\%) or parents who were deemed neglectful (40.0\%). Among the seven cases of alleged sexual abuse, three involved sexual penetration and four were cases of molestation. Children who were neglected were more likely to come from families with

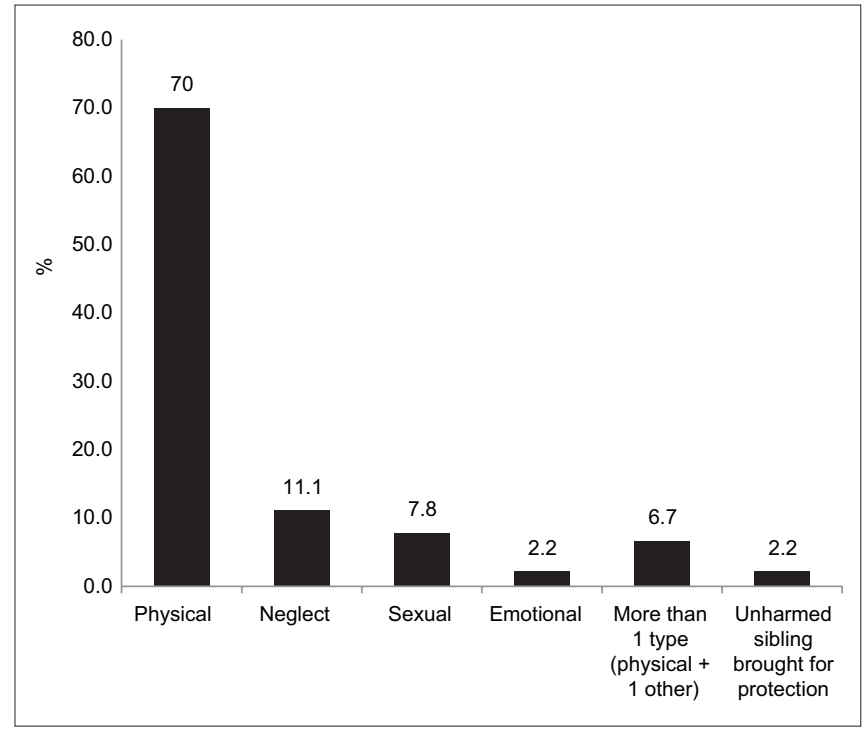

Fig. 4 Bar graph shows the subtypes of child maltreatment observed in the present study.

Table II. Demographic and socioeconomic characteristics of the children $(n=89)$.

\begin{tabular}{lc}
\hline Variable & No. (\%) \\
\hline Gender & $48(53.9)$ \\
Male & $41(46.1)$ \\
Female & \\
Ethnicity & $36(40.4)$ \\
Chinese & $45(50.6)$ \\
Malay & $4(4.5)$ \\
Indian & $4(4.5)$ \\
Others & \\
Socioeconomic risk factor & $59(66.3)$ \\
Prior history of domestic violence & $41(46.1)$ \\
Family with financial difficulty & $39(43.8)$ \\
Divorced/separated parents & $4(4.5)$ \\
Experienced the death of a parent & $15(16.9)^{*}$ \\
Parent with a mental health problem
\end{tabular}

*Alcohol abuse: $9 / 15$ (60.0\%); drug abuse, depression, acute stress reaction and/or intellectual impairment: $6 / 15$ (40.0\%).

Table III. Comparison of the characteristics of the children $(n=89)$ according to whether they were neglected or abused.

\begin{tabular}{lccc}
\hline Characteristic & \multicolumn{2}{c}{ No. (\%) } & p-value \\
\cline { 2 - 3 } & $\begin{array}{c}\text { Neglected } \\
(\mathbf{n}=\mathbf{1 0})\end{array}$ & $\begin{array}{c}\text { Abused* } \\
(\mathbf{n}=\mathbf{7 9 )}\end{array}$ & \\
\hline Prior history of domestic violence & $3(30.0)$ & $56(70.9)$ & $0.028^{+}$ \\
Family with financial difficulty & $9(90.0)$ & $32(40.5)$ & $0.005^{+}$ \\
Divorced/separated parents & $6(60.0)$ & $33(41.8)$ & 0.323 \\
Parent with a mental health problem & $3(30.0)$ & $12(15.2)$ & 0.363 \\
Previously known to CPS & $4(40.0)$ & $22(27.8)$ & 0.470 \\
Presence of developmental disorder & $2(20.0)$ & $12(15.2)$ & 0.654 \\
Presence of mental health condition & 0 & $9(11.4)$ & 0.590 \\
History of severe medical problems & $2(20.0)$ & $5(6.3)$ & 0.176 \\
\hline
\end{tabular}

${ }^{*}$ Includes physical, sexual or emotional abuse. ${ }^{\dagger} \mathrm{A} p$-value $<0.05$ was considered statistically significant. CPS: child protection services 
financial difficulty, as compared with those who were physically, sexually or emotionally abused $(p=0.005)$. Children who were victims of physical, sexual or emotional abuse were more likely to live in homes with a prior history of domestic violence $(p=0.028)$, as compared with those who were neglected (Table III).

The majority of the children were not reported to have any severe medical conditions (Table IV). Atopic disorders, such as asthma and eczema, were the most common medical problems. In most of the cases, the medical records did not document concerns about the child's early childhood development. However, $14(15.7 \%)$ of the children were diagnosed with one or more developmental disorders, the most common diagnosis being ADHD, followed by learning difficulties, global developmental delay and intellectual disability. The diagnoses were made by a psychiatrist or paediatrician using the criteria listed in the 4th edition of the Diagnostic and Statistical Manual of Mental Disorders, and were reported in the case notes of these children. ${ }^{(10)}$ Children who had a developmental disorder were found to be more likely to have a parent with a mental health disorder $(p=0.002$; Table V).

Reported behavioural problems were common, even among the children with no formal Axis I mental health diagnosis. Overall, parental concerns about the child's behaviour were reported in $31.5 \%$ of the cases. Among the 23 children who had one or more developmental or psychiatric disorders, $8(34.8 \%)$ received the diagnosis prior to their hospitalisation, while $15(65.2 \%)$ were diagnosed with the disorder during their hospital stay. The diagnosis was made by a child psychiatrist in $40.9 \%$ of the cases and by a paediatrician in $27.3 \%$ of the cases. For the remaining $31.8 \%$, the diagnosis was listed in the child's past history, but its source was not stated in the medical records. Among the 15 children who received their diagnosis as inpatients, the following interventions were initiated: (a) referral to the Child Development Unit; (b) art therapy; (c) behavioural therapy; (d) psychotherapy and counselling; (e) child life therapist intervention; (f) medications, including methylphenidate and fluoxetine; (g) outpatient paediatric follow-up; and/or (h) community- and school-based support. Three of the 23 children who had one or more developmental or psychiatric disorders were not documented as having received any intervention. Additionally, some children with no formal diagnoses had documented inpatient interventions such as art therapy, child life therapist intervention and counselling.

Most of the children were able to return to their family of origin (Fig. 5). In cases where the child was assigned to only one parent, the biological mother was the parent assigned in $93.3 \%$ of the cases. However, nearly one-quarter of the children were removed from their family of origin and placed in institutions (e.g. children's homes) or foster care.

\section{DISCUSSION}

The present study examined not only the demographic and social characteristics of children who were victims of alleged maltreatment, but also their medical, developmental and behavioural profile. Our findings add to previous research ${ }^{(7-9)}$
Table IV. Medical, developmental and mental health disorders identified in the medical records of the children $(n=89)$.

\begin{tabular}{|c|c|}
\hline Variable & No. (\%) \\
\hline \multicolumn{2}{|l|}{ Medical disorder } \\
\hline Atopic disorders (e.g. asthma and eczema) & $10(11.2)$ \\
\hline Ex-preterm & $2(2.2)$ \\
\hline $\begin{array}{l}\text { Chronic illnesses } \\
\text { (e.g. epilepsy, heart disease and liver disease) }\end{array}$ & $3(3.4)$ \\
\hline \multicolumn{2}{|l|}{ Developmental disorder } \\
\hline None & $75(84.3)$ \\
\hline Attention-deficit/hyperactivity disorder (ADHD) & $5(5.6)$ \\
\hline Learning difficulties, including dyslexia & $3(3.4)$ \\
\hline Global developmental delay & $2(2.2)$ \\
\hline Intellectual disability (ID) & $1(1.1)$ \\
\hline Autism spectrum disorder & $1(1.1)$ \\
\hline Isolated speech delay & $1(1.1)$ \\
\hline$A D H D+I D$ & $1(1.1)$ \\
\hline \multicolumn{2}{|l|}{ Mental health disorder* } \\
\hline None & $80(89.9)$ \\
\hline Conduct disorder & $2(2.2)$ \\
\hline Acute situational reaction & $2(2.2)$ \\
\hline Adjustment disorder & $1(1.1)$ \\
\hline Oppositional defiant disorder & $1(1.1)$ \\
\hline Post-traumatic stress disorder & $1(1.1)$ \\
\hline Obsessive compulsive disorder with social phobia & $1(1.1)$ \\
\hline Eating disorder, not otherwise specified & $1(1.1)$ \\
\hline
\end{tabular}

*Positive Axis I mental health problem.

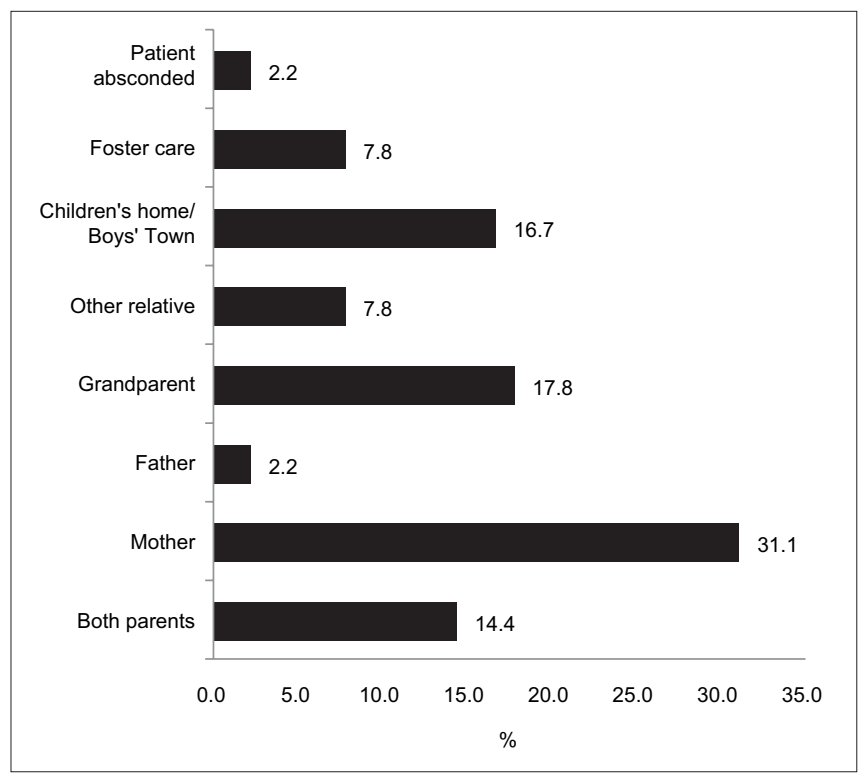

Fig. 5 Bar graph shows the assignment of caregivers at discharge.

in Singapore and have clinical implications for medical professionals.

In terms of the types of maltreatment and the profile of the perpetrators, our findings are similar to those reported in the MCYS publication. ${ }^{(8)}$ Most of the children admitted for alleged CMS were of school-going age; the peak ages of the children corresponded to the years of transition to primary and secondary 
Table V. Comparison of the characteristics of the children $(n=89)$ according to the presence or absence of developmental disorder(s).

\begin{tabular}{|c|c|c|c|}
\hline \multirow[t]{2}{*}{ Characteristic } & \multicolumn{2}{|c|}{ No. (\%) } & \multirow[t]{2}{*}{ p-value } \\
\hline & $\begin{array}{l}\text { With developmental } \\
\text { disorder(s) }(n=14)\end{array}$ & $\begin{array}{l}\text { Without developmental } \\
\text { disorders }(n=75)\end{array}$ & \\
\hline Family with financial difficulty & $8(57.1)$ & $33(44.0)$ & 0.396 \\
\hline Prior history of domestic violence & $8(57.1)$ & $51(68.0)$ & 0.539 \\
\hline Divorced/separated parents & $4(28.6)$ & $35(46.7)$ & 0.252 \\
\hline Parent with a mental health problem & $7(50.0)$ & $8(10.7)$ & $0.002^{*}$ \\
\hline Previously known to CPS & $6(42.9)$ & $20(26.7)$ & 0.336 \\
\hline Neglected child & $3(21.4)$ & $8(10.7)$ & 0.401 \\
\hline Presence of mental health condition & $3(21.4)$ & $6(8.0)$ & 0.147 \\
\hline History of severe medical problems & 0 & $7(9.3)$ & 0.344 \\
\hline
\end{tabular}

*A p-value $<0.05$ indicated statistical significance. CPS: child protection services

schools (i.e. ages seven and 13 years, respectively). This may suggest that school is a significant stressor to the parent-child relationship in the Singapore setting. The findings of the present study also suggest that school teachers and counsellors are often astute in identifying signs of child maltreatment. Therefore, for younger children who are not yet attending childcare centres or preschools (i.e. confined within their family units), it is important to screen for CMS in the medical setting.

Among the parents with a mental health problem, alcohol abuse was the most common condition. This is consistent with the findings summarised in a World Health Organization (WHO) fact sheet on child maltreatment and alcohol, which reported high rates of parent-offenders acting under the influence of alcohol or drugs. ${ }^{(5)}$ Prior history of domestic violence and financial difficulty were also highly prevalent. Therefore, the priority of clinicians should be to direct vulnerable and high-risk families to appropriate financial and social support so as to proactively reduce child abuse and neglect.

The prevalence of developmental difficulties in our study cohort was $15.7 \%$. This is higher than the population prevalence rate published by the MSF, where the disability prevalence rate was at least $3.2 \%$ in the preschool population (i.e. children aged $0-6$ years) and $1.5 \%$ in the school-age population (i.e. children aged 7-18 years). ${ }^{(1)}$ The population prevalence figures from the MSF publication may have been an underestimation of the actual prevalence of developmental disabilities in Singapore. The population prevalence of developmental difficulties was reported to be $13.87 \%$ in the United States ${ }^{(12)}$ and $7.0 \%$ in Australia. ${ }^{(13)}$ There are a number of other studies from these countries that have reported an even higher prevalence of developmental delay among children who had been maltreated. For example, one study conducted in a preschool overseen by the child protection services in Australia identified developmental delay or behavioural problems in $91 \%$ of the assessments. ${ }^{(14)}$ In another study that used a nationally representative sample of maltreated infants and toddlers in the United States, almost half of the children studied performed poorly in one or more developmental domains 18-36 months after investigation for abuse. ${ }^{(15)}$

The most common developmental disorder among the children in the present study was ADHD. This finding is consistent with that of studies conducted in other settings. It is likely that multiple genetic and environmental factors have contributed to this finding. Children with ADHD often have challenging behaviours, which may lead to parental stress and a higher chance of their parents resorting to physical punishment. ${ }^{(16)}$ Conversely, due to the heritability of ADHD, parents of such children may also exhibit more impulsive behaviour, leading to the verbal or physical abuse of their children. Paediatricians should not only screen for developmental problems in children with a history of maltreatment, but also enquire about developmental and mental health problems in their parents.

The lifetime incidence of mental health disorders in Singapore is estimated to be $12 \% .{ }^{(17)} \mathrm{A}$ mental health survey conducted by $\mathrm{WHO}$ found that approximately half of all lifetime mental health problems manifest in mid-teens. ${ }^{(18)}$ In the present study, $10.1 \%$ of the children had a positive Axis I mental health diagnosis before the age of 16 years, suggesting that this group of children has a higher lifetime risk of mental health disorders.

A sizeable proportion of the children involved in the present study were victims of repeated maltreatment requiring re-hospitalisation. This is of great concern, as it suggests that the causes of CMS in these families have yet to be adequately rectified. There is thus a need to carefully assess the safety of the home environment and maintain close surveillance of these children and their families following discharge from hospital.

We acknowledge that the present study has some limitations. Due to the retrospective nature of the study, the information gathered was dependent on the quality of documentation in the inpatient case notes, particularly regarding details of early developmental milestones and schooling. While most diagnoses such as ADHD, global developmental delay and intellectual disability were recorded in the case notes by physicians, some documented diagnoses were obtained via parent reports and could not be verified using information in the medical chart. The child's family history of mental health disorders was also obtained from documented history. However, important components of the child's history were usually systematically obtained the time of hospital admission and at subsequent inpatient encounters.

Additionally, we acknowledge that other key demographic information about the alleged perpetrators (e.g. age, ethnicity, 
educational level, occupation, family income and median household size), which would be important for comparison with the Singapore population, was not analysed in the present study. However, as this study was a retrospective chart review, we were constrained by the information available. These variables should be examined in future prospective studies.

We also noted that the extent to which the children were evaluated and monitored for developmental and mental health problems varied greatly. It is possible that some children who had such problems were not identified, diagnosed and followed up in the outpatient setting. To address this, we are currently piloting an inpatient developmental screening programme that screens for developmental and behavioural issues in children admitted for CMS; if such issues are identified, appropriate assessments, early intervention and outpatient follow-up of the children's progress will be recommended. We believe that screening this group of high-risk children will not only increase the rate of timely identification, but also enable early interventions to be carried out to help these children and their families cope better. This may help to reduce the rate of recurrence of CMS. The screening process is also expected to identify high-risk attitudes and behaviours in parents and caregivers, allowing timely referral to parent training groups and emotional health services.

To conclude, we have outlined a descriptive study of children admitted for alleged CMS in a single paediatric unit. Developmental and behavioural difficulties were found in a significant proportion of the children reviewed, and most of the children reviewed were from households with various social and financial stressors. Prevention and identification of child maltreatment should be a high priority for healthcare and social work professionals. A high index of suspicion should be exercised when dealing with households that have been previously investigated for child maltreatment issues. There should also be increased effort to reduce the long-term negative impact of child maltreatment on the children involved. This can be done via active screening for developmental and behavioural problems within the population, as well as interventions to address the problems identified.

\section{ACKNOWLEDGEMENTS}

This study was supported by a grant from the Singapore Children's Society, Singapore. We would like to express our gratitude to Dr Serena Tung, Consultant; Dr Chong Shang Chee, Head and Consultant of the Child Development Unit (CDU), National
University Health Systems (NUHS), Singapore; and the rest of the NUHS CDU for their support. We also thank Dr Dimple Rajgor, Medical Writer, NUHS for her help in editing, formatting and submitting the manuscript for publication.

\section{REFERENCES}

1. World Health Organization. Health topics: Child maltreatment [online]. Available at: http://www.who.int/topics/child_abuse/en. Accessed April 30, 2014.

2. Edwards VJ, Holden GW, Felitti VJ, Anda RF. Relationship between multiple forms of childhood maltreatment and adult mental health in community respondents: results from the adverse childhood experiences study. Am J Psychiatry 2003; 160:1453-60.

3. Sugaya L, Hasin DS, Olfson M, et al. Child physical abuse and adult mental health: a national study. J Trauma Stress 2012; 25:384-92.

4. Thornberry TP, Henry KL, Smith CA, et al. Breaking the cycle of maltreatment: the role of safe, stable, and nurturing relationships. J Adolesc Health 2013; 53(4 Suppl):S25-31.

5. World Health Organization. Child maltreatment and alcohol [online]. Available at: http://www.who.int/violence_injury_prevention/violence/ world_report/factsheets/fs_child.pdf. Accessed April 30, 2014.

6. Spencer N, Devereux E, Wallace A, et al. Disabling conditions and registration for child abuse and neglect: a population-based study. Pediatrics 2005; 116:609-13.

7. Cengel-Kültür E, Cuhadaroğlu-Cetin F, Gökler B. Demographic and clinical features of child abuse and neglect cases. Turk J Pediatr 2007; 49:256-62.

8. Ministry of Social and Family Development, Singapore. Child Abuse Investigations [online]. Available at: http://app.msf.gov.sg/ResearchRoom/ ResearchStatistics/ChildAbuselnvestigations.aspx. Accessed April 30, 2014.

9. Ministry of Community Development, Youth and Sports, Singapore. Protecting Children in Singapore. Available at: http://app.msf.gov.sg/ portals/0/Summary/research/Materials_Protect_Children_in_Spore.pdf. Accessed April 30, 2014.

10. American Psychiatric Association. Diagnostic and Statistical Manual of Mental Disorders. 4th eds, text rev. Washington, DC: American Psychiatric Association, 2000

11. Ministry of Social and Family Development. Singapore. Available Data on Disability in Singapore. Available at: http://app.msf.gov.sg/Portals/0/Files/ EM_Annex.pdf. Accessed April 30, 2014.

12. Boyle CA, Boulet S, Schieve LA, et al. Trends in the prevalence of developmental disabilities in US children, 1997-2008. Pediatrics 2011; 127:1034-42.

13. Australian Bureau of Statistics. Children with a disability. Available at: http://www.abs.gov.au/AUSSTATS/abs@.nsf/Lookup/4102.0Main+ Features30Jun+2012. Accessed April 30, 2014

14. McDonald JL, Milne S, Knight J, Webster V. Developmental and behavioural characteristics of children enrolled in a child protection preschool. J Paediatr Child Health 2013; 49:E142-6.

15. Scarborough AA, Lloyd EC, Barth RP. Maltreated infants and toddlers: predictors of developmental delay. J Dev Behav Pediatr 2009; 30:489-98.

16. Alizadeh H, Applequist KF, Coolidge FL. Parental self-confidence, parenting styles, and corporal punishment in families of ADHD children in Iran. Child Abuse Negl 2007; 31:567-72.

17. Chong SA, Abdin E, Vaingankar JA, et al. A population-based survey of mental disorders in Singapore. Ann Acad Med Singapore 2012; 41:49-66.

18. Kessler RC, Angermeyer M, Anthony JC, et al. Lifetime prevalence and age-of-onset distributions of mental disorders in the World Health Organization's World Mental Health Survey Initiative. World Psychiatry 2007; 6:168-76. 